\title{
A não utilização dos procedimentos operacionais padrão por profissionais de saúde em um centro de diálise
}

\author{
The non-use of the standard operating procedures by health \\ professionals in a dialysis centre
}

Lidiane Peixoto de Almeida ${ }^{1}$ E Elaine Antunes Cortez $^{2} \bullet$ Geilsa Soraia Cavalcanti Valente $^{3}$ - Stephan Melro Rego ${ }^{4} \bullet$ Aline Figueiredo Ferreira ${ }^{5} \bullet$ Adriana Cortez Marcellos Fernandes $^{6}$

\begin{abstract}
RESUMO
Objetiva-se identificar se a equipe de saúde utiliza os Procedimentos Operacionais Padrão no momento do cuidado prestado ao paciente em hemodiálise, e descrever as possíveis dificuldades para implementação dos Procedimentos Operacionais Padrão pela equipe no contexto da hemodiálise. Trata-se de um estudo descritivo de abordagem qualitativa, com realização de entrevistas com questionário semi-estruturado e analisado à luz de Laurence Bardin, realizado em um hospital universitário no Estado do Rio de Janeiro. Participaram da entrevista semi-estruturada $85 \%$ dos profissionais da unidade entre médicos, residentes médicos, residentes de enfermagem, enfermeiros, técnicos e auxiliares de enfermagem, entre os meses de maio e junho de 2016. Foram encontradas três categorias, agrupadas no formato de citações diretas do referencial filosófico utilizado na dissertação original, Paulo Freire, como demonstrado no decorrer deste estudo. Conclui-se que os resultados nos levam a reflexão sobre a importância da Educação Permanente em Saúde para a informação e debates para melhor adesão dos Procedimentos Operacionais Padrão nas unidades assistenciais.
\end{abstract}

Palavras-chave: Hemodiálise; Acreditação Hospitalar; Educação Permanente; Atenção Terciária à Saúde; Educação em Saúde.

\begin{abstract}
It aims to identify if the health team uses the Standard Operating Procedures at the time of the hemodialysis patient care and to describe the possible difficulties for the implementation of the Standard Operating Procedures by the team in the context of hemodialysis. This is a descriptive study of a qualitative approach, with semistructured questionnaires and analyzed in the light of Laurence Bardin, carried out in a university hospital in the State of Rio de Janeiro. Participated in the semi-structured interview $85 \%$ of the unit professionals between doctors, medical residents, nursing residents, nurses, technicians and nursing assistants in the period from May to June 2016. Three categories were found, grouped in the format of direct citations of the philosophical reference used in the original dissertation, Paulo Freire, as demonstrated in the course of this study. It concludes that the results lead us to reflect on the importance of Permanent Education in health for the information and debates for better adherence of the Standard Operating Procedures in the care units.
\end{abstract}

Keywords: Renal Dialysis; Hospital Accreditation; Continued Education; Tertiary Healthcare; Health Education.

${ }^{1}$ Mestre em Enfermagem pela Universidade Federal Fluminense- UFF. E-mail: Lidianelpa@hotmail.com. Endereço: Rua General Pereira da Silva,193, apartamento 1101, Icaraí, cidade Niterói/ R, Brasil, CEP 24220-030.Autor correspondente.

${ }^{2}$ Doutora em Enfermagem. Professora Adjunto do Departamento de Enfermagem Materno-Infantil e Psiquiatria, Escola de Enfermagem Aurora de Afonso Costa da Universidade Federal Fluminense-UFF.E-mail: nanicortez@hotmail.com.

${ }^{3}$ Doutora em Enfermagem. Professora Adjunto de Departamento de Fundamentos de Enfermagem e Administração, Escola de Enfermagem Aurora de Afonso Costa da Universidade Federal Fluminense - UFF. E-mail: geilsavalente@yahoo.com.br.

${ }^{4}$ Especialista em Análise, Projeto e Gerência de Sistemas. Integrante do Núcleo de Pesquisa Trabalho, Saúde e Educação. Tecnologista em Saúde Pública na Fundação Oswaldo Cruz. E-mail: stephan_melro@yahoo.com.br.

${ }^{5}$ Mestranda em Enfermagem pela Universidade Federal Fluminense-UFF.E-mail: alinefigueiredoferreira@hotmail.com.

${ }^{6}$ Mestre. Educadora Física e Fisioterapeuta. Fundação de Apoio à Escola Técnica. E-mail: terapeuta.adriana@outlook.com. 


\section{INTRODUÇÃO}

A preocupação com a qualidade na prestação de serviços em saúde não é recente e a finalidade do paciente ao necessitar dos serviços hospitalares é de restabelecer sua saúde, solucionar problemas e equilibrar as disfunções. Para que se possa usufruir de um serviço de qualidade é necessário um sistema gerencial que reconheça as suas necessidades, estabeleça padrões e busque mantê-los para assegurar a sua satisfação ${ }^{1}$. $O$ gerenciamento da qualidade pode ser útil, contribuindo com a implementação de novas metodologias e mudanças necessárias para melhoria da assistência e contentamento da equipe e do paciente ${ }^{2}$.

Um gerenciamento de qualidade necessita passar por uma padronização.A melhor forma de iniciar a padronização é através da compreensão de como ocorre todo o processo, nesse caso é necessária uma representação sistematizada: um exemplo é o Procedimento Operacional Padrão (POP). 0 POP descreve cada passo crítico e sequencial que deverá ser dado pelo profissional de saúde para garantir o resultado esperado da tarefa, além de relacionar-se à técnica, palavra de origem grega que refere-se à "disposição pela qual fazemos coisas com a ajuda de uma regra verdadeira"1-3.

Os atos técnicos induzem a ação repetida, às vezes, por muitas mãos diferentes, com alguma garantia de mesmo resultado. Entretanto, os profissionais de saúde, diferentes com talentos, sentimentos e conhecimentos, deveriam agir com regularidade do mesmo modo, mas produzem, nem sempre, com meios exatamente iguais em razão dos contextos do trabalho, resultados próximos ao esperado para uma assistência considerada de boa qualidade ${ }^{3}$.

Para que o portador de doença renal crônica receba uma assistência de qualidade, as técnicas de cuidado ofertadas devem ter sido pensadas de forma a diminuir riscos e danos, trazendo segurança ao profissional e ao paciente. Os POPs são um dos norteadores de uma prática de maior qualidade.

A Insuficiência Renal Crônica é uma doença crescente. Segundo censo realizado pela Sociedade Brasileira de Nefrologia (SBN)4, em julho de 2013, o número de pacientes em tratamento dialítico foi de 100.397. A diálise apresenta-se como um tratamento para a substituição da função de filtração dos rins, com duas modalidades: a diálise peritoneal e a hemodiálise.

O cenário de estudo apresenta três espaços para tratamento renal: um setor de internação e transplante renal, um setor para acompanhamento e treinamento em diálise peritoneal, e um setor para hemodiálise. Nesta pesquisa, foi utilizado o espaço da hemodiálise que é, na grande parte das vezes, onde o paciente renal precisa entrar em um ambiente hospitalar para receber o seu tratamento.

Desta forma, a atuação do enfermeiro no processo saúde-doença do paciente renal crônico é indispensável, pois o mesmo atua na educação e direciona o tratamento adequado frente às complicações da doença, preparando a equipe de enfermagem para cuidar dos pacientes submetidos à hemodiálise, em todos os aspectos, sejam eles físicos, biológicos e psicossociais ${ }^{5}$.

Os POPs ficam contidos em manuais com a finalidade de esclarecer dúvidas e orientar a execução das ações e devem estar de acordo com as diretrizes e normas da instituição, e serem atualizados sempre que necessário, de acordo com princípios científicos que deverão ser seguidos por todos (médicos, enfermeiros e auxiliares) de forma padronizada 6 .

Tendo a hemodiálise como a principal forma de tratamento para a doença renal crônica, é necessária uma orientação prévia aos profissionais e pacientes, pois lidar com uma deficiência que representa um risco à vida significa ter uma mudança radical de hábitos e cuidado para ambos. Portanto, é essencial que o paciente renal crônico seja motivado por profissionais capacitados para aceitar os novos hábitos diários e que conscientize-se sobre a grave doença que o acomete, bem como a necessidade de aderir ao tratamento.

O tratamento é conservador, a terapia nutricional no tratamento do renal crônico tem como meta reduzir o acúmulo de compostos tóxicos provenientes do metabolismo proteico, minimizar a ocorrência de distúrbios metabólicos como acidose, resistência insulínica, hiperparatireoidismo secundário, hipercalemia e hipertensão, prevenir o desenvolvimento de desnutrição e ainda possivelmente, retardar o ritmo de progressão da insuficiência renal crônica. A principal manipulação dietética que atinge a maior parte desses objetivos é a restrição de proteínas. Os pacientes são acompanhados por uma equipe multiprofissional que contribui para a identificação da progressão da doença renal crônica por meio de tratamentos adequados, como o início da terapia antihipertensiva com inibidores da enzima conversora de angiotensina, rigoroso controle glicêmico nos casos de diabetes, dieta adequada indicada pelo nutricionista e adoção de hábitos de vida saudáveis? .

É muito importante que o enfermeiro esteja atento às queixas e reações apresentadas pelo paciente, pois assim ele conseguirá adotar medidas para a amenização das necessidades apontadas. A realização de educação em saúde e um bom trabalho humanizado podem ter resultados positivos na qualidade de vida de seus pacientes e familiares. Também há uma necessidade do envolvimento contínuo de uma equipe multiprofissional para a garantia de uma assistência de qualidade e livre de riscos ${ }^{8}$.

0 estudo contribuiu com o surgimento de melhor qualidade da assistência, proporcionando aos profissionais da área de saúde, melhor instrumentalização para o cuidado e condições para o planejamento da assistência integral ao paciente em processo hemodialítico.

No ensino, contribuiu com o estímulo a implementação de atualização constante por meio do desenvolvimento de ações educativas no Centro de Diálise, podendo ser extensível a todas as unidades assistenciais que não possuem. 
Na pesquisa, serviu de instrumentação para o debate e a reflexão sobre o tema entre os profissionais e estudantes da área de saúde, atualização sobre o que existe de mais recente publicado acerca desta temática e publicação de artigos científicos.

Sendo assim, as questões que nortearam o estudo foram: a equipe utiliza os Procedimentos Operacionais Padrão no momento do cuidado prestado ao paciente em hemodiálise? Quais as possíveis dificuldades encontradas para implementar os Procedimentos Operacionais Padrão no contexto da hemodiálise?

Os objetivos foram identificar se a equipe utiliza os POPs no momento do cuidado prestado ao paciente em hemodiálise; e descrever as possíveis dificuldades para implementação dos POPs pela equipe no contexto da hemodiálise.

\section{MÉTODO}

Este estudo foi precedido da aprovação do Comitê de Ética em Pesquisa (CEP) da Universidade Federal Fluminense. Após aprovação pelo CEP, número de parecer 1.478.802 de 05 de abril de 2016, e da assinatura do Termo de Consentimento Livre e Esclarecido dos participantes com a intenção de manter o anonimato e respeitar os preceitos éticos da resolução 466/12 do Conselho Nacional de Saúde - Ministério da Saúde (CNS/MS), foi realizada a pesquisa.

Trata-se de uma pesquisa descritiva, de abordagem qualitativa, por meio de entrevistas com questionário semiestruturado, analisado de acordo com Laurence Bardin, desenvolvida entre os meses de maio e junho de 2016.

Foi realizado em um hospital de atenção terciária localizado no estado do Rio de Janeiro, em um Centro de Diálise. Utilizou-se a análise de conteúdo de Bardin, pois julgou-se ser a mais adequada para alcançar os objetivos propostos.

Triviños ${ }^{9}$ e Manzini ${ }^{10}$ têm tentado definir e caracterizar o que vem a ser uma entrevista semi-estruturada. Para Triviños 9:146 "a entrevista semi-estruturada tem como característica questionamentos básicos que são apoiados em teorias e hipóteses que se relacionam com o tema da pesquisa". Os questionamentos dariam frutos a novas hipóteses que surgem a partir das respostas dos informantes. 0 foco principal será colocado pelo investigador-entrevistador. Complementa o autor, afirmando que a entrevista semi-estruturada "[...] favorece não só a descrição dos fenômenos sociais, mas também sua explicação e a compreensão de sua totalidade [...]" além de manter a presença consciente e atuante do pesquisador no processo de coleta de informações ${ }^{9: 152}$.

A análise de conteúdo, originalmente, representa um instrumento de pesquisa empregado para determinar a presença de algumas palavras ou conceitos subjacentes dentro de um texto ou conjunto de textos, a partir da análise dos dados e das relações entre eles, com a finalidade de fazer inferências sobre as mensagens contidas no texto.

Bardin $^{11: 134}$ refere que

A análise de conteúdo assenta implicitamente na crença de que a categorização (passagem de dados brutos a dados organizados) não introduz desvios, por excesso ou por falta, no material, mas que revela índices invisíveis, ao nível dos dados brutos.

Os critérios de inclusão utilizados na seleção dos sujeitos foram: funcionários que estavam de serviço em passagem ou recebimento de plantão, funcionários que eram lotados no Centro de Diálise e ligados a assistência ao paciente. Excluídos os profissionais de licença ou férias, e os que não tinham ligação direta com a assistência em sala de hemodiálise.

0 setor conta com aproximadamente 50 profissionais, porém os que estavam dentro dos critérios de inclusão e exclusão, quarenta. A amostra de profissionais foi composta de 34 profissionais de saúde que responderam a entrevista, o que equivale a $85 \%$ do total pretendido, composta de 05 enfermeiros (14,7\%), 02 residentes de enfermagem (5,9\%), 04 médicos (11,8\%), 5 residentes de medicina (14,7\%), 06 técnicos de enfermagem (17,6\%) e 12 auxiliares de enfermagem (35,3\%).

Para melhor identificação do leitor acerca dos trechos das entrevistas individuais, foram utilizadas as iniciais da categoria profissional seguida de um algarismo arábico, conforme explicado nos resultados, antes das falas dos participantes no momento da análise das categorias.

As perguntas utilizadas para nortearem a entrevista semi-estruturada foram: você sabe o que é Procedimento Operacional Padrão (POP)? Você considera importante para uma instituição hospitalar? Você utiliza os Procedimentos Operacionais Padrão da sua unidade? Por quê? O roteiro de entrevista foi previamente testado.

As entrevistas foram gravadas em arquivo digital (MP3 player) e posteriormente transcritas na íntegra.

\section{RESULTADOS}

As categorias estão identificadas da seguinte maneira, letra $\mathrm{E}$ para Enfermeiros; letra $M$ para Médicos; letras TE para Técnicos de enfermagem; letras AE para Auxiliares de enfermagem; letras RM para Residentes Médicos; letras RE para Residentes de enfermagem.

Através da análise dos dados, emergiram três categorias principais, nas quais foram utilizadas citações diretas do pensador Paulo Freire: 1. "Ninguém educa ninguém, ninguém educa a si mesmo, os homens se educam entre si, mediatizados pelo mundo"12:95; 2. "Se a educação sozinha não transforma a sociedade, sem ela tampouco a sociedade muda"13:67; 3. "Ensinar não é transmitir conhecimento, mas criar as possibilidades para a sua própria produção ou a sua construção"14:24. 
1. "Ninguém educa ninguém, ninguém educa a si mesmo, os homens se educam entre si, mediatizados pelo mundo"12:95

O POP foi visto pelos entrevistados como um conjunto de normas e rotinas.

"POP são as rotinas de procedimento de cada unidade, de cada serviço, por exemplo na nossa área que é a hemodiálise você tem rotina de desinfecção, rotina de operação de máquina, rotina de controle de infecção, etc" (M 3).

A equipe destacou que o POP confere ao funcionário a segurança de estar fazendo o procedimento corretamente.

\begin{abstract}
“E a padronização é de extrema importância porque ela impede que os erros aconteçam, porque se eu fizer sempre daquele mesmo jeito, daquela mesma maneira você evita que erros sejam cometidos porque você já está treinado assim, de uma certa maneira" (E 1).
\end{abstract}

Alguns participantes relataram que o POP nos remete à segurança do profissional e do paciente, importantes para inibir erros e complicações evitáveis, e a retirada de dúvidas:

"E quando acontece um quadro de infecção ou uma coisa qualquer você não sabe quem foi que errou e aonde que teve o erro" (E 2).

\section{2."Se a educação sozinha não transforma a sociedade, sem ela tampouco a sociedade muda" 13:67}

Os profissionais relataram que não seguem o POP porque não entendem a sua importância:

"Ah eu acho que tinha que ser uma coisa mais objetiva, eu não acho o POP uma coisa muito objetiva"(E 2).

“[...] não é padronizado, cada um faz de um jeito. Cada um ensina de um jeito, mas não adianta, o POP não funciona." "...você quer fazer como está escrito ali no POP, mas você não consegue porque as próprias pessoas falam: não faz assim porque não vai dar certo. Como você vai fazer?"(AE 8).

Enquanto os POPs forem vistos e revisados apenas por alguns, e não apresentados a todos, sua adesão será mínima, tal como o seu estímulo à utilização:

"É difícil, né... porque ninguém quer ler [...]"(AE 2).

“Não sei o que é, então não saberia dizer se eu o utilizo. Posso estar utilizando, e não saber que isso é um procedimento padrão"(RM 1).

Para muitos profissionais, o formato do pop não é atraente:

"Eu acho que o POP tinha que mudar a forma como ele é feito, acho a forma que é feito muito chata" (E 2).
Os profissionais também colocaram a estrutura física como um elemento dificultador para a aproximação com os POPs, pois sua acessibilidade é limitada:

“Porque eu não as vejo, não sei onde estão, é, eu acho que elas ficam muito escondidas e não é uma coisa de fácil acesso, eu acho que tem que ser mais claramente anunciado aonde que está. É, para as pessoas manusearem e saberem do que se trata [...]" (M 1).

A estrutura de materiais também impede a execução das práticas dentro da técnica padronizada por falta de material (levando a improvisação):

"Porque às vezes a gente se encontra impossibilitado de executar na íntegra, mas a gente... eu pelo menos, eu consigo chegar próximo como tem que ser. Porque às vezes a gente tem que improvisar as coisas" (AE 1).

“Mas porque têm que improvisar?"(Entrevistador).

"Falta de material" (AE 1).

Outra dificuldade colocada pelos profissionais foi a dificuldade de recursos humanos, ou seja, a sobrecarga dos funcionários à demanda da unidade, cujo comprometimento com a rotina impede a leitura dos POPs:

"[...] a demanda da gente era muito grande e às vezes a gente acaba se perdendo um pouco, porque é pouco técnico para muito paciente, e a gente acabava passando por cima dos padrões que manda a prática..." (AE 1).

\section{3. "Ensinar não é transmitir conhecimento, mas criar as possibilidades para a sua própria produção ou a sua construção"14:24}

A equipe, na área da educação, mostrou a necessidade de ser manter atualizada, de alguma forma, para conhecerem o POP:

“[...] se você se reúne com a equipe, se você faz com que participe, têm uma adesão muito maior" (E 1).

Como grande parte são confeccionados pela chefia de enfermagem como requisito obrigatório,acabou sendo visto como mais um pré-requisito da ANVISA ao funcionamento da unidade do que um instrumento de boas práticas.

"Os POPs são importantes, agora, a crítica que eu te faço é que muitas vezes o POP é feito e normalmente são as enfermeiras que fazem, fica numa pasta bonita e é colocada num armário e as pessoas não acessam de novo, mas está lá para a Vigilância Sanitária ou para outro órgão de fiscalização ver. O que eu acho é que precisa... mais divulgação dos mesmos" (M 3).

Os participantes também demonstraram que precisam de uma gestão mais atuante e que seja mais vigilante acerca da adesão aos POPs: 
"Sendo observado isso o tempo todo porque senão aquilo fica lá dentro de um livro e a gente continua fazendo as coisas antigas [...]" (AE 4).

Alguns profissionais apontaram a necessidade de motivação como uma das formas de adesão aos POPs:

“[...] dificilmente a gente encontra uma chefia que motive, uma chefia que utilize de ferramentas gerenciais para incentivar e estimular esse funcionário a continuar trabalhando de acordo com as normas... tem que trabalhar a motivação profissional, sem a motivação a gente não tem essa operação, a gente não consegue implantar nada" (E 5).

\section{DISCUSSÃO}

$1^{\text {a }}$ Categoria: "Ninguém educa ninguém, ninguém educa a si mesmo, os homens se educam entre si, mediatizados pelo mundo"12:95

A relação da frase de Paulo Freire ${ }^{12: 95} \mathrm{com}$ a primeira categoria diz respeito ao papel do POP na unidade, sendo um instrumento de auxílio aos profissionais, não ter conquistado os mesmos na busca de uma melhor assistência. Um instrumento educativo que não cumpriu o seu papel.

"Não basta saber ler que Eva viu a uva. É preciso compreender qual a posição que Eva ocupa no seu contexto social, que trabalha para produzir a uva e quem lucra com esse trabalho"15:22.

Não basta saber que o POP existe, é preciso mostrar a sua importância no contexto hospitalar, e a importância de se estar familiarizado com o mesmo.

O POP é visto pelos entrevistados como um conjunto de normas e rotinas.

0 ambiente hospitalar refere 0 restabelecimento da saúde de pessoas doentes que já trazem consigo problemas de ordem orgânica e psicológica. 0 cuidado para a melhora do seu quadro clínico depende de como o mesmo será prestado. O POP tem como objetivo ajudar na padronização do cuidado e o fato de ser visto como norma já cria uma espécie de separação, pois uma regra não cumprida tem como consequência a punição.

Os POPs devem ser do conhecimento de todos para que a equipe adote o cuidado de acordo com as suas regras, e façam parte do dia a dia dos que executam seus procedimentos.

Paulo Freire, em seu livro Pedagogia do Oprimido, traz "...que a reflexão, se realmente reflexão, conduz à prática"12:73.

A valorização do serviço confere valor aos executores do cuidado, pois um ambiente avaliado positivamente se dá graças ao trabalho coletivo da equipe, todos ganham com um trabalho bem feito: a equipe, o paciente e o hospital.

A equipe destaca que o POP confere ao funcionário a segurança de fazer o procedimento corretamente.
As transformações constantes das práticas advindas de pesquisas que buscam melhorar e aprimorar os cuidados ao paciente, fazem com que a equipe de saúde esteja nesse contexto de modificações e transformações, e pode, em algum momento, sentir-se desatualizada, pois a educação como ferramenta de gerenciamento nesta unidade não é tão ativa e eficaz a ponto de retirar essa insegurança.

Deste modo, é possível afirmar que a padronização das rotinas propicia maior segurança na realização dos procedimentos. Entretanto, compete ao enfermeiro, ao elaborar os POPs junto à sua equipe, implementar e controlar as ações assistenciais permeado pela visão de integralidade do paciente ${ }^{17}$.

Alguns participantes relataram que o POP nos remete à segurança do profissional e do paciente, importantes para inibir erros e complicações evitáveis, e a retirada de dúvidas.

A segurança do paciente é uma bandeira nova para questões antigas presentes dentro dos hospitais brasileiros. O POP contém em seu conceito a questão central relativa à segurança do paciente, pois uma técnica realizada dentro dos seus moldes, traz uma atuação o mais livre de danos possível.

O POP faz parte da gestão da qualidade, estando presente em seus procedimentos para obter a manutenção dos resultados. O POP é retratado como uma "descrição sistematizada e padronizada de uma atividade técnicaassistencial, com o intuito de garantir/atingir o resultado esperado por ocasião de sua realização, livre de variações indesejáveis"18:2.

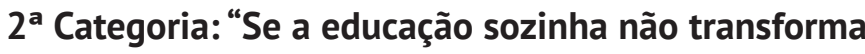 a sociedade, sem ela tampouco a sociedade muda"13:67}

A relação da frase de Paulo Freire ${ }^{13}$ com a segunda categoria diz respeito à necessidade de apresentação dos POPs aos funcionários do Centro de Diálise, pois se os POPs existem dentro da unidade e as pessoas não o seguem, está faltando a adesão por parte dos profissionais, e isso só pode ser feito se ele de fato estiver sido apresentado, implantado, ensinado e cobrado de quem deveria seguir suas instruções.

Os profissionais relataram que não seguiam o POP porque não entendiam a sua importância. O POP não tem se mostrado eficaz em seu papel dentro do Centro de Diálise, pois profissionais que exercem cargos maiores levavam a profissionais que estão sob sua supervisão instruções acerca do que não estava preconizado, por falta de esclarecimento e/ou por não ter participado da construção daquele instrumento que foi feito para a sua unidade, junto aos que construíram.

Paulo Freire nos remete à reflexão acerca da educação como prática da liberdade, quando nos escreve que ao contrário daquela que é prática da dominação, implica a negação do homem abstrato, isolado, solto, desligado 
do mundo como uma realidade 'ausente dos homens' ${ }^{\prime 10}$. A prática da dominação não permite a construção conjunta, o que faz com que o outro não se sinta parte daquela construção, que deveria ser seguida por todos.

Enquanto os POPs forem vistos e revisados apenas por alguns, e não construídos por todos, sua adesão será mínima, tal como o seu estímulo à utilização.

A equipe deve participar e ter consciência das normas de uma organização para que se possa aderir às mesmas.

Paulo Freire ${ }^{14}$ nos atesta que o educador democrático, coerente, competente, que testemunha seu gosto pela vida, sua esperança no mundo melhor, que atesta sua capacidade de luta, seu respeito às diferenças, sabe cada vez mais o valor que tem para a modificação da realidade.

O profissional enfermeiro deve saber a importância de manter uma Educação Permanente em Saúde (EPS) dentro de uma unidade para que as regras, como as que contém nos POPs, deixem de ser algo não atraente para uma ferramenta importante a ser utilizada na sua prática e na prática daqueles que ele gerencia. É importante que o enfermeiro reconheça o seu papel de educador e busque formas de trazer para a sua realidade propostas necessárias a uma assistência de qualidade.

O fato do POP ser um passo a passo, um conjunto de regras, escrito em um papel sem, mais uma vez, ser mostrada a sua importância, faz com que o mesmo tenha essa forma difícil de ser posta em prática, uma vez que não há formas mais atualizadas de se passar o conteúdo, e o fato de ele ser bastante detalhado, fica cansativa e desestimulante a sua leitura.

O POP do Centro de Diálise fica contido em uma pasta, grande e pesada, contendo os procedimentos operacionais padrão de todo o serviço do hospital, não só os utilizados no Centro de Diálise. Depois desse momento, foi criada uma segunda pasta, que fica dentro da sala branca (sala de hemodiálise), menor, apenas com os procedimentos que são feitos dentro da sala ou relacionadas à hemodiálise em si.

Esse momento de entrevista é importante porque por meio da enquete pôde-se trazer melhorias de acessibilidade dos POPs, houve uma obra de marcenaria na secretaria trazendo divisórias para que todo o material, inclusive os POPs, ficassem mais visíveis dentro da unidade.

A estrutura de materiais também impede a execução das práticas dentro da técnica padronizada por falta de material (gerando improvisações).

A falta de material é uma velha conhecida, infelizmente, de todos os hospitais públicos brasileiros. Em todo momento, notícias são veiculadas nas emissoras de rádio e televisão devido à falta de insumos essenciais para o trabalho, levando não só a quebra de técnicas, prejudicando a segurança de paciente e profissionais, mas a diminuição e até interrupção de serviços e diminuição de leitos.

O processo de adaptar e improvisar materiais e equipamentos tem um grande potencial para trazer repercussões psicofísicas nos trabalhadores devido às circunstâncias em que elas são criadas, ou seja, em um contexto de precarização das condições de trabalho ${ }^{19}$.

Outra questão colocada pelos profissionais é a dificuldade de recursos humanos, ou seja, a sobrecarga dos funcionários à demanda da unidade, cujo comprometimento com a rotina impede a leitura dos POPs.

Para que o POP faça parte do dia a dia dos profissionais, não é preciso interromper as atividades do setor, mas encaixá-las de modo que seja possível e não atrapalhe a rotina, como a Educação Permanente em Saúde.

A aprendizagem em serviço alimenta-se da relação dialética entre esses pares de elementos com base em erros e problemas e se concentra na colaboração entre iguais. A situação de trabalho torna-se também, desde a ótica de aprendizagem, situação de exploração e de investigação ${ }^{20}$.

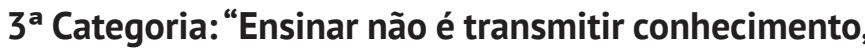 mas criar as possibilidades para a sua própria produção ou a sua construção"14:24}

A relação da frase de Paulo Freire ${ }^{14}$ com a terceira categoria diz respeito às formas de se passar o conhecimento para que o mesmo seja posto em prática pela equipe, pois a forma como é passado o conhecimento é que pode trazer aos profissionais a questão da adesão, por ter sido conquistado por aquela idéia/iniciativa.

A equipe, na área da educação, mostrou a necessidade de manter-se atualizada, de alguma forma, para que saibam sobre o POP.

Diante da expectativa de criação, de interação, podese dizer que os agentes são aqueles que interagem e a interação é o que provoca a ação inovadora ou ação atualizada que faça mais sentido aos atores sociais que seriam os próprios trabalhadores ou usuários ${ }^{20}$.

Infelizmente ainda temos dentro do Centro de Diálise alguns profissionais que não sabem o que é, ou do que se trata, ou onde estão, os POPs da unidade.

Como grande parte é confeccionada pela chefia de enfermagem como requisito obrigatório, os POPs acabam sendo vistos como mais um pré-requisito da ANVISA ao funcionamento da unidade do que um instrumento de boas práticas.

Para a consolidação do SUS, torna-se fundamental investir na formação e no desenvolvimento de seus trabalhadores, aqui considerados como agentes de mudanças. Na construção de conhecimentos, habilidades e atitudes, as ações educativas devem ser compreendidas, para além do sentido clássico da aquisição de conhecimentos técnico científicos, como um processo de produção de sujeitos críticos e reflexivos, de transformação da realidade e de criação de novas formas de gestão dos processos de trabalho ${ }^{21}$.

Os participantes também demonstraram que precisam de uma gestão mais atuante e que seja mais vigilante 
acerca da adesão aos POPs, embora a chefia diga que não tem como cobrar enquanto os POPs não estiverem atualizados.

A deficiência com relação à qualidade nos serviços de saúde resulta em sérios impactos para a sociedade e os sistemas de saúde, manifestando-se de muitas formas, como, por exemplo, serviços ineficazes, que não alcançam os resultados esperados; serviços ineficientes; inacessíveis, tanto geográfica, econômica, como cultural ou socialmente, refletindo em longas listas e insatisfação dos usuários e profissionais de saúde 22 .

Esse cenário é causado por fatores, como falta de priorização da qualidade na agenda do setor saúde; deficiência dos marcos regulatórios (normas técnicas, sistemas de acreditação e habilitação e cartas de deveres e direitos dos pacientes), formação de profissionais de baixa qualidade e inadequada para a gestão de recursos materiais, humanos e financeiros, falta de programas de desenvolvimento profissional, transferência financeira desconectada com o desempenho e os resultados de saúde, ausência de trabalho em equipe, modelo paternalista de assistência que não envolve o usuário na tomada de decisão e condições de trabalho inadequadas ${ }^{(22)}$.

Uma organização só pode ter sucesso quando a proposta ou o processo vem da gestão, cada um deve assumir o seu papel: tanto o enfermeiro como o supervisor das ações de enfermagem, como os técnicos e auxiliares de enfermagem como os principais executores do cuidado. O médico como prescritor, executor e supervisor das ações médicas e dos residentes de medicina. A coordenadora da unidade como supervisora do cuidado de todos.

A saída pela educação, que pode ser feita em qualquer setor sem grandes intervenções de níveis macro, se dá pela Educação Permanente em Saúde. Se essa educação trouxer a todos conscientização de suas práticas, a correção será feita durante as reuniões, sem precisar chamar os profissionais nominalmente para que a forma correta seja repassada.

São evidentes as tensões nesse processo: a problematização sobre o processo de trabalho produz mobilização e questionamentos de várias ordens. Incômodo para a gestão se não se deseja democratizar processos de decisão ou não ter como enfrentar os problemas identificados ${ }^{21}$.

Apesar das tensões, não houve limitação no estudo.

A busca pela competência, pelo conhecimento e pela atualização é essencial para garantir a sobrevivência de um profissional e de uma profissão. A contribuição da educação permanente na prática profissional evidencia-se por meio das atitudes que o profissional assume enquanto cuida, dentre as quais está o compromisso firmado consigo mesmo, mediante a motivação pela busca do autoconhecimento, do aperfeiçoamento e da atualização, e prevendo melhorar o cuidado prestado ao cliente e à comunidade. A educação permanente leva ao entendimento de que o indivíduo deve ter no autoaprimoramento uma meta a ser seguida por toda sua vida ${ }^{23}$

\section{CONCLUSÃO}

As categorias oriundas das entrevistas após análise de conteúdo são reveladoras, quando em seu contexto, apontam para um desconhecimento do que é o POP, ou, quando sabiam do que se tratava o $P O P$, não utilizavam em grande parte das vezes. São gritos que retratam o intenso movimento vivido pelos profissionais que atuam no Centro de Diálise no cotidiano de suas atividades práticas.

As dificuldades para a adesão passam por questões de informação sobre o que é e a importância dos POPs, não participação coletiva na sua construção, sobrecarga de recursos humanos, falta de material na unidade, e uma gestão que tenha o interesse de trabalhar fortemente com a questão.

Compreendendo a importância do serviço do Centro de Diálise de um hospital do SUS, formador de recursos humanos na área de saúde, e seu papel nas políticas que direcionam a assistência em nefrologia, temos como expectativa que os resultados desta pesquisa contribuam para que outros hospitais que possuam o Centro de Diálise com unidade de hemodiálise possam refletir sobre seus problemas cotidianos e trazer resolutividade por meio da Educação Permanente em Saúde, como foi realizada nesta unidade.

\section{REFERÊNCIAS}

1. Nogueira LCL. Gerenciando pela qualidade total na saúde. 4. ed. Belo Horizonte: Editora de Desenvolvimento Gerencial; 2003.

2. Antunes AV, Trevizan MA. Gerenciamento da qualidade: utilização no serviço de enfermagem. Rev Latino-am Enfermagem. 2000; 8(1):35-44.

3. Schraiber LB, Peduzzi MSA, Sala A, Nemes MIB, Castanhera ERL, Kon R. Planejamento, gestão e avaliação em saúde: identificando problemas. Ciênc Saúde Coletiva [Internet].1999 [acesso em: 3 Nov 2016]; 4(2):221-242. Disponível em: http:// www.scielo.br/scielo.php?script=sci_arttext \&pid=S141381231999000200002 \&lng=en \&nrm=iso.

4. Sesso RC, Lopes AA, Thomé FS, Lugon JR, Santos DR. Inquérito Brasileiro de Diálise Crônica 2013 - Análise das tendências entre 2011 e 2013. J Bras Nefrol. 2014; 36(4):476-481.

5. Araújo ACS, Santo EE. A Importância das Intervenções do Enfermeiro nas Intercorrências durante a Sessão de Hemodiálise. Caderno Saúde e Desenvolvimento [Internet]. 2012 jul-dec [acesso em: 3 nov 2016]; 1(1):44-58. Disponível em:https://www.uninter.com/revistasaude/index.php/ cadernosaudedesenvolvimento/article/viewFile/137/72.

6. Silva VEF. Manuais de enfermagem. In: Kurcgant $P$, coordenadora. Administração em enfermagem. São Paulo: Editora Pedagógica e Universitária; 1991. p. 59-72.

7. Riella MC. Princípios de nefrologia e distúrbios hidroeletrolíticos. Rio de Janeiro: Guanabara Koogan; 1996. 
8. Fidelis $\mathrm{Cl}$, Balbino CM, Souza MMTE, Rodrigues LMS, Silvino ZR, Passos JP. Dificuldades enfrentadas pelo paciente renal para a realização do tratamento. Revista Enfermagem Atual. 2016; 15(1):16-21.

9. Triviños ANS. Introdução à pesquisa em ciências sociais: a pesquisa qualitativa em educação. São Paulo: Atlas; 1987.

10. Manzini EJ. Considerações sobre a elaboração de roteiro para entrevista semi-estruturada. In: Marquezine MC, Almeida MA, Omote S, organizadores. Colóquios sobre pesquisa em Educação Especial. Londrina: EDUEL; 2003. p.11-25.

11. Bardin L. Análise de conteúdo. Lisboa: Edições 70; 2009.

12. Freire P. Pedagogia do Oprimido. 59. ed. Rio de Janeiro: Paz e Terra; 2015. 253p.

13. Freire P. Pedagogia da indignação: cartas pedagógicas e outros escritos. São Paulo: UNESP; 2000.134p.

14. Freire P. Pedagogia da Autonomia: saberes necessários à prática educativa. 50. ed. Rio de Janeiro: Paz e Terra; 2015.

15. Freire P. A educação na cidade. São Paulo: Cortez; 1991.

16. Guerrero GP, Beccaria LM, Trevizan MA. Standard operating procedure: use in nursing care in hospital services. Rev. Latino-Am. Enfermagem [Internet]. 2008 Dez [acesso em: 9 set 2016]; 16(6): 966-972. Disponível em: http://www.scielo. br/pdf/rlae/v16n6/05.pdf.

17. Almeida ML, Segui MLH, Maftum MA, Labronici M, Peres AM. Instrumentos gerenciais utilizados na tomada de decisão do enfermeiro no contexto hospitalar. Texto Contexto Enferm [Internet]. 2011 [acesso em: 8 nov 2016]; 20(Spe): 1317. Disponível em: http://www.scielo.br/pdf/tce/v20nspe/ v20nspea17.pdf.

18. Hospital Getúlio Vargas. Procedimento Operacional Padrão Enfermagem. Teresina: HGV; [Internet]. 2012 [acesso em: 17 nov 2016]. Disponível em: http://www.hgv.pi.gov.br/ download/201207/HGV20_d747ba8b2b.pdf.

19. Souza NVDO, Santos DM, Ramos EL, Anunciação CT, Thiengo PCS, Fernandes MC. Repercussões psicofísicas na saúde dos enfermeiros da adaptação e improvisação de materiais hospitalares. Esc. Anna Nery [Internet]. 2010 Jun [acesso em: 23 nov 2016]; 14(2):236-243. Disponível em: http://www. scielo.br/pdf/ean/v14n2/04.pdf.

20. EPS em movimento. Educação e trabalho em saúde: a importância do saber da experiência. Educação Permanente em Saúde em Movimento [Internet]. 2014 [acesso em: 8 nov 2016]. Disponível em: http://eps.otics.org/material/entradatextos/educacao-e-trabalho-em-saude-a-importancia-dosaber-da-experiencia.

21. Ministério da Saúde (Brasil), Secretaria-Executiva. Subsecretaria de Assuntos Administrativos. O Trabalho como fonte de formação: um movimento em construção no Ministério da Saúde - Agenda 2015 de Desenvolvimento dos Trabalhadores. Brasília: Ministério da Saúde [Internet]. 2015. [acesso em: 8 nov 2016]. Disponível em: http://bvsms. saude.gov.br/bvs/publicacoes/trabalho_fonte_formacao_ movimento_construcao.pdf.

22. Manzo BF, Ribeiro HCTC, Brito MJM, Alves M. Nursing in the hospital accreditation process: practice and implications in the work quotidian Rev. Latino-Am. Enfermagem [Internet] 2012 Feb [acesso em: 23 nov 2016]; 20(1):151-158. Disponível em: http://www.scielo.br/pdf/rlae/v20n1/20.pdf.
23. Paschoal AS, Mantovani MF, Lacerda MR. A educação permanente em enfermagem: subsídios para a prática profissional. Rev Gaúcha Enferm. 2006; 27(3): 336-43. 